International Conference on Renewable Energies and Power Quality (ICREPQ'11)

Las Palmas de Gran Canaria (Spain), 13th to 15th April, 2011

\title{
Comprehensive utilization of energy in sugar factory using renewable energy sources, maximizing the power cogeneration.
}

\author{
E. Gil, L.A. Bujedo, L. Gorostiaga \\ FUNDACIÓN CARTIF \\ Parque Tecnologico de Boecillo,parc. 205, \\ 47151 Boecillo (Valladolid), SPAIN \\ Phone/Fax number:+0034 983 546504, email:enrgil@cartif.es, luibuj@cartif.es, lazgor@cartif.es
}

\begin{abstract}
.
In this paper we evaluate the implementation of renewable energy to process sugar and alcohol production. This has been applied to dynamic simulation techniques that provide quantitative information production in a Caribbean climate.
\end{abstract}

\section{Key words}

Renewable energy, sugar production, dynamic simulation, dried bagasse.

\section{Introduction}

The solar energy applications are many and varied: water heating, refrigeration production, ovens, dryers, etc. However, its application in an industrial level faces certain barriers and reticence that makes difficult its implementation:

Most industries are subjected to continuous production processes, which can not depend upon the availability of solar radiation, which in fact is capricious and in a specific way random, even if it is in terms of mean energy.

The elements devoted to transforming solar energy have low energy density; therefore, large areas are required to have enough energy and thus have some impact in the whole process.

The renewable energy based systems are generally not straightforward integrated into industrial production systems.

The usual rates of return in the companies are 2-3 years, although solar facilities are distance runners that can give benefits over longer periods (10-20 years). This statement is supported by the durability of these facilities, and considering a promising scenario in which prices are increasing for thermal energy based on burning fossil fuels, and electricity based on centralized production, and further transport and distribution to consumption points.

On the other side, the production plants present some advantages:

As they are continuous processes, their energy consumption are quite regular. Therefore, there are always available options for the use of renewable energy.

The production plants are generally large area facilities, thus helping in the placement of large quantities of solar collectors.

They have a wide variety of energy demands and thus, there are several points within the processes that can be exploited.

Hence, it is necessary to develop new initiatives for industrial applications that can provide experience and demonstrate the feasibility of solar energy in production environments

The IEA (Inernational Energy Agency) has been sensitive to this issue, under its program of Solar Heating and Cooling during the years 2003-2007. They analysed the applicability of solar energy in industry throughout the [1] Task 33 - Solar Heat for Industrial Processes, establishing the potential application of solar energy as a function of its thermal level.

Previously, [2] Dufie and Beckman in 1991, proposed some industrial actions for heating of both water and air, these being the two most commonly used fluids. They also showed some examples of industrial facilities, especially in the food industry. 
In this paper we present a possible application of renewable energy, for its inclusion in the production process of sugar cane, which is a very important industry in Latin America. Furthermore, the area has access to high levels of solar radiation, which can promote its implementation.

Within the sugar cane production must be controlled at least 15 key points in the production system, which in the case of the proposed article will focus on 5: Control of water flow and temperature of imbibition, and control steam pressure in boiler flue gas boiler, boiler water level control power and bagasse boiler.

On these points are those that develop the application of automation in the production process of sugar cane proposed in this paper.

\section{Development}

One of the main characteristics of solar facilities is their loose of performance, as the temperature difference between ambient and heated water increases. Such phenomena is mainly due to the increased system losses in the collector's own production as well as accumulation.

In this paper, we have been identified the points at which renewable energy can be harnessed to improve process energy.

For the application of solar energy, we have identified three possible applications:

1. In the process of extraction of juice from sugar cane (whether you use a mill train as if you use a diffuser bagasse) is necessary to use hot water. The flow rate of water imbibition.

The function of a sugar factory is to produce crystals from cane juice, therefore the efficiency of extraction of juice on a train grinding or in a diffuser affects profitability.

In the extraction process, the raw is cane prepared which comprises a solid part called fiber and a liquid part, the juice, which contains water and sucrose. Both parties are also other substances in very small quantities.

The proportions of the components vary with the variety of sugarcane, however, a general reference values can be: water from $73 \%$ to $76 \%$ sucrose from $8 \%$ to $15 \%$ and fiber between $11 \%$ and $16 \%$.

The percentage of solids (sucrose and other substances) found in $100 \%$ juice is called Brix.
Typically, in a sugar mill in Latin America, the process of extracting sugarcane juice is made in a mill train as shown in Figure 1.

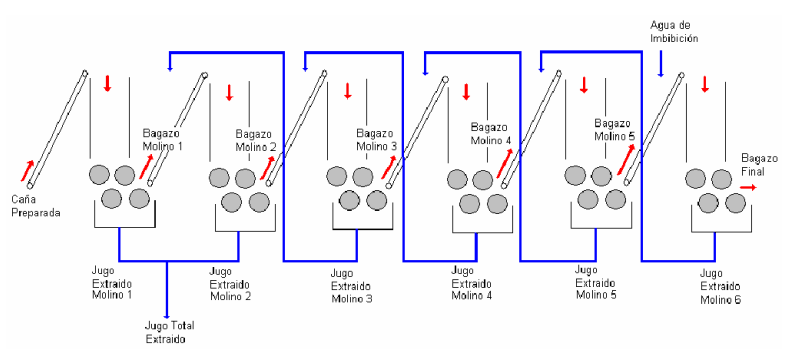

Figure 1: Model of a train with imbibition water in the sixth mill

The extraction process starts with feeding the prepared cane to the first mill hopper through a conveyor belt.

At the mill, the cane is extracted nearly $70 \%$ of the juice and the rest remains in the bagasse which goes to the next mill by another band. In each of the mills is repeated the extraction process to the last, where the pulp comes out the end is approximately $2.5 \%$ of Brix and $50 \%$ humidity.

To improve the extraction process, water is usually applied at a temperature of $90^{\circ} \mathrm{C}$ at the entrance of the last mill.

The amount of water depends on the amount of fiber in the pulp. Normally applies a $200 \%$ flow of bagasse fiber. The juices from these mills is applied to the input of the former mills in the process of embedding compound. The juice extracted from the first mill along with the extracted in the second mill goes to the next stage of the process of making sugar. The total extracted juice typically has between $15 \%$ to $20 \%$ Brix. Figure 1 shows the model of a train with imbibition water in the sixth mill.

For example, a mill to process 18.000 tons / day of cane need 195 ton / h of water at $90^{\circ} \mathrm{C}$ for imbibition

2. Secondly, the juice extracted from the sugar cane must be heated from inlet temperature $\left(30^{\circ} \mathrm{C}\right)$ up to $105^{\circ} \mathrm{C}$. Typically, this heat input takes place in two steps: firstly by a primary heater, which uses plant steam released during the process, and seconly by using exhaust air steam heating.

For example, a mill that processes $18,000.00$ tons / day of cane needed to heat approximately 18.900 ton / day of juice.

3. Lastly, the heating contribution to a bagasse dryer through air plenums. 
In a well-balanced sugar factory, the bagasse produced is to supply all its domestic energy needs while remaining amount should be close to $25 \%$.

This amount of remaining bagasse can produce and supply renewable electricity to the national electrical grid.

In the sugar cane plantations in Latin America it has been done traditionally, but is intensifying in recent times with the advent of the Kyoto Protocol.

One ton of bagasse at $50 \%$ moisture produces about 2.15 tons of steam, and 5.8 tons of bagasse $(50 \%$ moisture) equals 1 ton of oil.

Today we try to reduce the moisture of bagasse to increase its caloric value and increase sales of electricity.

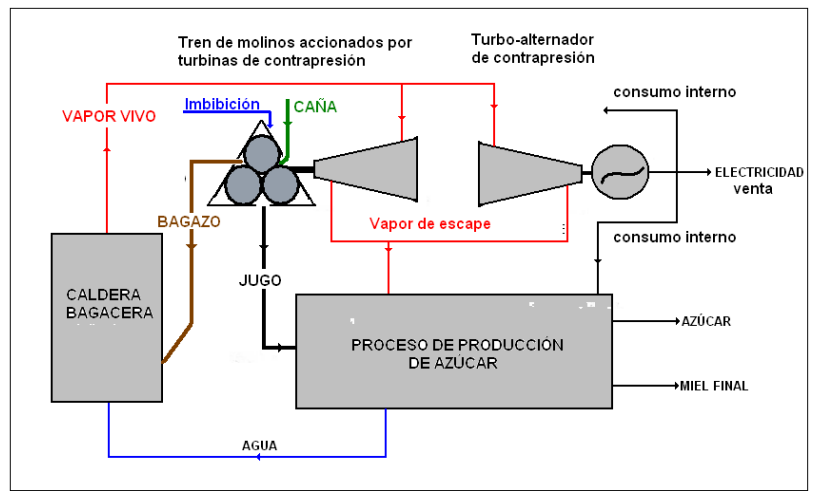

Figure 2: Typical pattern traditional bagasse cogeneration in sugar mills American

In the figure 2 shows the typical pattern traditional bagasse cogeneration in sugar mills American.

\section{Results}

In this work we have made an analysis of the energy efficiency per unit for those three potential applications, using dynamic simulation time. In such a manner, the ratios and values of relevance, performance and energy contribution to the environment of South of Mexico have been considered.

Control development within this comprehensive energy use will be to integrate the production process of solar heating techniques to control water flow and temperature of imbibition and integrate mixed feeding a bagasse boiler.

These mixixed feeeding consisting of bagasse with $40 \%$ moisture before drying instalation adjacent to the sugar cane production process, and use to turn off agricultural crop residues (RAC).[8] [10]

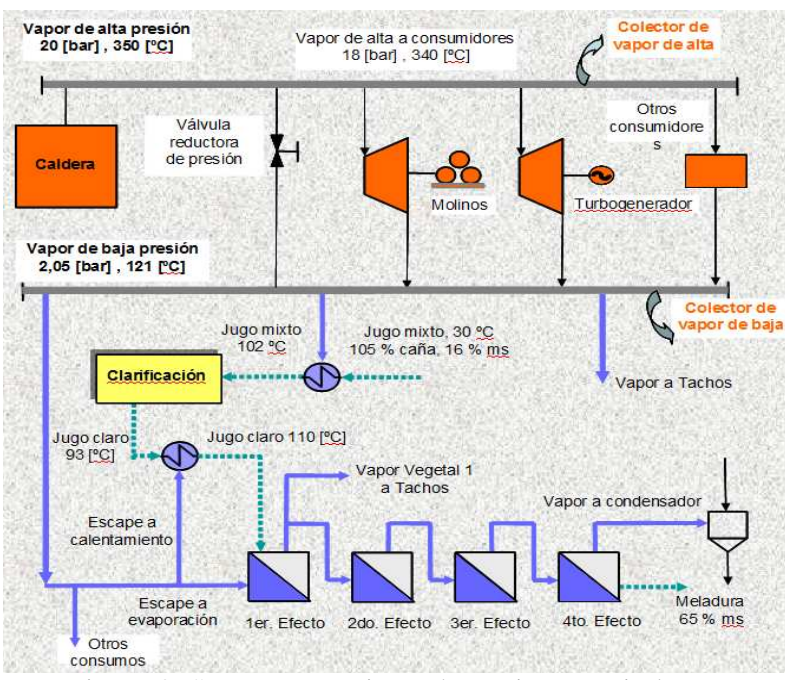

Figure 3. Steam generation scheme in sugar industry

As we have seen in the figure 3 , this modification in process system give a very significant increase in the level of steam [6] [7] in boilers and therefore in the level of turbine electricity production, thereby increasing energy cogeneration.

To perform the simulation data have been taken, city of Tapachula weather in southern Mexico (182 m), on the edge of the border with Guatemala, with a climate typical of Central America with an annual energy incident on horizontal surface of $1.841 \mathrm{kWh} / \mathrm{m}^{2}$ for $\mathrm{yr}$.

To obtain numerical values for to make a quantitative analysis of improvements and yields, there has been a dynamic simulation in TRNSYS [3] environment, considered a reference facility of $100 \mathrm{~m}^{2}$ of solar collectors medium-performance high $(0.75$ and efficicency intercept slope efficiency $4 \mathrm{~W} / \mathrm{m}^{2}{ }^{\circ} \mathrm{C}$ ).

Since the latitude is $14.92{ }^{\circ} \mathrm{N}$, and is intended to maximize production during the wet season, it has been a penchant for collecting $30{ }^{\circ} \mathrm{C}$, assuming they are perfectly oriented to the south.

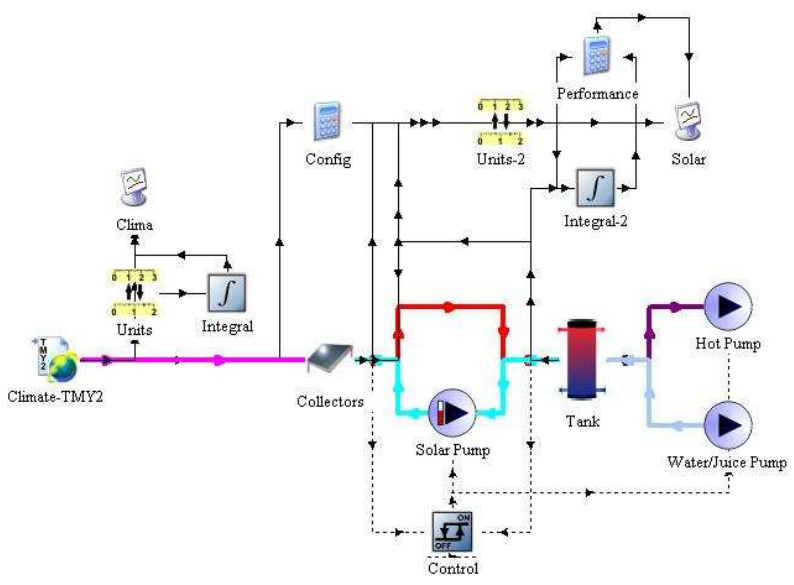

Figure 4: TRNSYS Scheme of simulation 
To perform the simulation, it was considered that the flow of the solar system is $50001 / \mathrm{h}$, taking a ratio of $50 \mathrm{l} / \mathrm{h} \cdot \mathrm{m}^{2}$, which is usual for such applications.

The accumulation is taken from 50001 in order to be able to cope at a time equivalent to the flow solar. It is supposed to stay in a room with an ambient temperature of $20^{\circ} \mathrm{C}$. The deposit is layered with uniform heat newspapers.

It has been assumed that the mill operates 24 hours a day during January, February, March, October, November and December.

They have raised two simulation scenarios for case studies 1 and 2 presented above. The basic difference is in the temperature of supply water / juice, which in the first case, the temperature of network, which has been an average of $20^{\circ} \mathrm{C}$, and in the second case, the juice from the process extraction, which has been an average temperature of juice on $30^{\circ} \mathrm{C}$.

To set the volume of applications, there has been a sensitive analysis of each of the cases, so that the average temperature jump out of the facility, equal to about $10^{\circ} \mathrm{C}$.

Noted that for high flows, the outlet temperature is reduced and the utilization is higher, giving the opposite situation with low flows.

It turns out that if imposed as a criterion, maximizing the energy supplied, there are high flows, but with little temperature jump between the input and output.

The control strategy implemented, is based on a control temperature differential between the bottom of the tank and collector output with a threshold of starting and stopping of $5^{\circ} \mathrm{C}$ and $2^{\circ} \mathrm{C}$ respectively.

\section{A CASE 1: WARM WATER INBIBICIÓN.}

To meet the criterion of $10^{\circ} \mathrm{C}$ temperature jump between the water network and taking advantage, it requires a flow of applications from $30001 / \mathrm{h}$, which corresponds to a ratio of $30 \mathrm{l} / \mathrm{h} \cdot \mathrm{m}^{2}$.[5] [6]

$B$

CASE 2: WARM THE JUICE.

The inlet temperature of juice in this case is $30^{\circ} \mathrm{C}$ and analysis to establish the flow of applications has given a slightly higher value of $3500 \mathrm{l} / \mathrm{h}$, corresponding one to one ratio per unit of solar surface of $35 \mathrm{l} / \mathrm{h} \cdot \mathrm{m}^{2}$.
Under these conditions, Table 1 shows the results obtained by the simulations in each of the two case studies:

Table 1: Results of simulation

\begin{tabular}{lccc}
\multirow{2}{*}{ VARIABLE } & \multicolumn{3}{c}{ VALOR } \\
& CASE 1 & CASE 2 & \\
\hline Solar energy incident & 97,187 & 95,850 & $\mathrm{kWh}$ \\
Energy collectors & 69,814 & 62,677 & $\mathrm{kWh}$ \\
Load Energy & 69,846 & 61,660 & $\mathrm{kWh}$ \\
Total Yield & 71.84 & 65.39 & $\%$ \\
Mean Temperature & 29.97 & 39.57 & ${ }^{\circ} \mathrm{C}$
\end{tabular}

In the first row shows energy incident on the solar field from the sun. In the second row, the energy that have become collectors and has been contributed to the accumulation. The third row shows the real power harnessed from the accumulation. The next row shows the performance of the solar field. Finally, we show the average temperature of use, which is about $10^{\circ} \mathrm{C}$ for both cases.

The reduction in the consumption of heat input from the bagasse boiler, in both cases, will allow the largest amount of heat to the cogeneration and thus the production of electricity, thereby increasing revenue from the sale to electrical network.

\section{CASE 3: HEATING CONTRIBUTION TO A BAGASSE DRYER THROUGH AIR PLENUMS.}

Bagasse Drying has been a rather controversial issue within various experts consulted by paper authors, [8] [9] to carry out this study in various aspects as the amount of moisture removed, problems with pressure and temperature increases in excess bagasse boilers, etc.

With the data collected of process in sugar factory, the advantage of drying the bagasse is clear, so much so as that for every $1 \%$ drop in the humidity of drying bagasse should provide approximately $1 \mathrm{Tm}$. less than bagasse to get the same conditions of pressure and temperature in boiler.

In another order of things, we see that as the drying of bagasse are checked the following incidents:

- It is impractical to dry bagasse moisture percentages needed to be pelletized this bagasse, both by volume of bagasse, for the time required for drying.

- Secondly, this pellet could not be used bagasse current bagasse boilers, since the maximum drop of moisture must be as much as $44-45 \%$ humidity, according to research for the paper, since less moisture would technical risks in operating boilers. 
- Then the only possibility, and with the reservations already mentioned in this section would be as a byproduct bagasse pellet production for sale as biomass fuel, with the economic qualifications since the production of the pellet would be costly and the selling price should be appropriate to do it.

\section{Conclusions}

Considering the low energy density of solar systems, it is mandatory to use large areas, which are generally available in industrial systems.

The performances obtained for the considered temperature levels are quite correct.

The yields are for treated temperature levels are correct.

The use of solar energy with the use of agricultural crop residues (RAC) and the drying of bagasse cause the increased generation of electricity is really high and therefore its profitability is good.

The advantage of drying the bagasse is clear, so much so as that for every $1 \%$ drop in the humidity of drying bagasse should provide approximately $1 \mathrm{Tm}$. less than bagasse to get the same conditions of pressure and temperature in boiler.

The maximum drop of moisture must be as much as 44 $45 \%$ humidity, according to research for the paper, since less moisture would technical risks in operating boilers.

The reduction in bagasse moisture will be done, through the use of hot air produced in a collector through the use of solar thermal and air / air exchanger for reduce the bagasse humidity in the terms stated in this paper.

\section{Bibliography}

[1] Task 33 - Solar Heat for Industrial Processes, http://www.iea-shc.org/task33/

[2] Duffie J.A. and Beckman W.A. Solar Engineering of Thermal Processes, 2nd (1991)Ed, Wiley-Interscience.

[3] TRNSYS: A transient Simulation Program 1990. Solar Energy Laboratory, University of Wisconsin, Madison

[4] Clauddia Vannoni, Ricardo Battisti, Serena Drigo, Potencial for Solar heat in industrial processes. Task 33 Solar heat industrial processes, 2008

[5] Honig, P.: Principios de Tecnología Azucarera.

[6] Spencer, M.: Manual de caña de azúcar
[7] Jenkins, G.: Introducción a la tecnología del azúcar de caña

[8] Feijóo, E.; Sosa, S.; Golato, M.; Paz, D.; Aso, G. y Cárdenas G.: Aprovechamiento del Resíduo Agrícola de Cosecha (RAC) dela caña de azúcar como combustible en calderas

[9] Bombino Matos E.F., Roca Alarcón G., Lesme Jaén R. : Perspectivas del secado de bagazo.

[10] H. N. Kudal, R. Pangavhane and G. V. Parishwad. Study of photovoltaic powered forced circulation solar tunner bagasse dryer. 